This is a post-peer-review, pre-copyedit version of an article published in Journal of Gepgraphical systems. The final authenticated version is available online at: https://doi.org/10.1007/s10109-017-0255-0

\title{
Pulling APART: NeW PERSPECTIVES ON THE SPATIAL DIMENSIONS OF NEIGHBOURHOOD INCOME DISPARITIES IN CANADIAN CITIES
}

\author{
(doi.org/10.1007/s10109-017-0255-0) \\ Sébastien Breau (corresponding author) \\ McGill University, Department of Geography \\ E-mail: sebastien.breau@mcgill.ca \\ Tel: (514) 398-3242; Fax: (514) 398-7437 \\ Michael Shin \\ UCLA, Department of Geography \\ E-mail:shinm@geog.ucla.edu \\ Nick Burkhart \\ UCLA, Department of Geography \\ E-mail: nickburkhart@ucla.edu \\ Submitted to: Journal of Geographical Systems
}

3 January 2017

4 Tables and 4 Figures

\begin{abstract}
The spatial configurations of changes in the distribution of incomes within Canada's eight largest metropolitan areas are examined using a new approach based on dynamic local indicators of spatial association. These changes are characterized by increasing spatial polarization (or divergence) between higher- and lower-income neighbourhoods in Montreal, Toronto, Ottawa-Gatineau, Calgary and Vancouver. Though patterns of spatial polarization are less pronounced in Edmonton, Winnipeg and Quebec City, several lower-income neighbourhoods in these cities nevertheless appear to be losing ground relative to other neighbourhoods. These neighbourhoods are characterized by higher levels of precarious employment and higher shares of visible minority and recent immigrant populations.
\end{abstract}

Key words: urban inequality; neighbourhood income disparities; spatial polarization; directional LISAs; micro-data; Canada

JEL codes: R23, I30, J31 and O51

Acknowledgements: Part of the analysis presented in this paper was conducted at the McGill-Concordia branch of the Quebec Interuniversity Centre for Social Statistics (QICSS). We are grateful to Kayla Wagg and Daniele Forest for their assistance with the micro-data files. Funding for this research was received by the Social Sciences and Humanities Research Council of Canada. The views expressed in this paper are those of the authors, and not necessarily those of the QICSS or its partners. 


\section{Introduction}

The issue of income inequality is at the forefront of public debate. Indeed, for most OECD countries, the last 30 years have been characterized by substantial increases in income inequality (OECD 2014). In some countries, like the US and UK, the surge in inequality is such that it has reached levels not seen in more than a century (Piketty 2014). Even in countries where inequality has traditionally been low, like Denmark, Finland and Sweden, the distribution of income is increasingly unequal.

Canada is no exception to this trend. In fact, from the early 1990s to the mid-2000s, income inequality increased in the country up to five times faster than the average across other OECD countries (OECD, 2014). To a large degree, this rise in inequality has been driven by the growing concentration of income among top-income earners (Fortin et al. 2012; Veall 2012; Breau 2014).

While there is an important body of literature documenting this trend at the national-level (see, for instance, Banting and Myles 2013; Green et al. 2016), much less is known about changes in the geography of inequality at the metropolitan scale. In a cross-city comparative study, Bolton and Breau (2012) find that the vast majority of Canadian cities have seen their levels of inequality increase, with larger metropolitan areas growing particularly more unequal over time. In a study focusing on Canada's largest urban areas, Chen et al. (2012) find that increasing inequality has led to a rise in neighbourhood inequality, along with an increase in spatial economic segregation. More recent work by Walks (2013; 2015; 2016) also finds that Canadian cities are becoming less equal as well as more polarized. The latter finding is particularly important to Walks who argues that more attention needs to be paid to the spatial dynamics of polarization across neighbourhoods. We still know little about how the trajectories of neighbourhood incomes, especially how differences between higher- and lower-income neighbourhoods, have changed over time and space. Is there really a tendency towards greater bipolarity in the spatial distribution of neighbourhood incomes?

These are the questions we take up in this paper. As we will argue below, to tackle the problem existing studies of neighbourhood inequality have relied on conventional measures of inequality and polarization. While these studies provide important insights into intra-urban distributional dynamics, they ignore the issue of spatial dependence (i.e., the local clustering of similar levels of income across a city). The focus of existing studies, in other words, has been mainly on comparing the distribution of neighbourhood incomes at two points in time and examining changes in the structural dimensions of neighbourhood inequality rather than changes in the underlying spatial configurations of income disparities. Thus, we do not know if there is a growing prevalence of clusters (or pockets) of higher- and 
lower-income neighbourhoods within metropolitan areas, nor do we know if the gap between these clusters is growing. Our goal is to address this shortcoming by using a newly developed approach that integrates dynamic local indicators of spatial association (LISA) with directional statistics to explore the individual movements of census tracts and their neighbours within each city's income distribution (see Rey et al. 2011; Murray et al. 2012).

After replicating results of earlier studies using conventional approaches, we find that in five of eight metropolitan areas considered the spatial configurations of changes in the distribution of incomes are characterized by increasing divergence between higher-vs. lower-income census tracts over the 1991 to 2006 period. On the one hand, the position of several higher-income neighbourhoods in Montreal, Toronto, Calgary, Vancouver and Ottawa-Gatineau has improved over time as they experienced relatively faster growth in incomes, while on the other hand several lower-income neighbourhoods have fallen behind. We also investigate differences in the socio-economic composition of these neighbourhoods which are pulling apart the spatial distribution of incomes. Finally, while the pattern of spatial polarization is less pronounced in Edmonton, Winnipeg and Quebec City, several lower-income neighbourhoods in these cities nevertheless appear to be losing ground relative to other neighbourhoods. These results contribute new insights to the literature with regards to changes in the spatial morphology of neighbourhood income disparities as well as to the movements (i.e., mobility) of neighbourhoods within metropolitan area income distributions. More broadly, they also show the relevance of directional LISA analysis to the study of increasingly complex patterns and processes of urban inequality.

\section{Reviewing the literature}

\section{Urban form and geographies of inequality}

Urban theorists have long sought to understand how the spatial organization of cities and their distribution of income evolves over time ${ }^{1}$. Among the earliest of explanations, Park and Burgess (1925) proposed a concentric ring theory, modeled on Chicago, whereby economic activity and land uses were neatly organized in different zones around the city's central business district (CBD). From this inner ring, the city transitioned from business to manufacturing and warehousing activities, followed by a working class residential zone, a middle class zone and eventually on the outer ring the commuter suburbs of

\footnotetext{
${ }^{1}$ Beveridge (2011) and Florida et al. (2014) provide good overviews of this literature.
} 
higher-income residents. Spatially, the distribution of income was thus organized in linear fashion along a positive gradient emanating from the CBD and the goal was to move from the inner to outer rings.

The 'Chicago School' model was subsequently modified by Hoyt (1939). Land uses, he argued, did not necessarily follow a pattern of outward radiating concentric rings. Instead, cities could expand in sectors which stretched from the $\mathrm{CBD}$ along major transportation routes or corridors of different economic activities.

With car ownership on the rise, yet another model was proposed by Harris and Ullman (1945). Instead of thinking about the city's spatial layout as anchored by a single CBD, Harris and Ullman argued that multiple nodes would emerge around different types of economic activities. The greater mobility of people meant that these nodes would eventually specialize and become distinct hubs and growth points within large and rapidly expanding metropolitan areas. Still, in terms of the income gradient, the more affluent residents would seek to steer clear of industrial clusters and choose to live in more suburban areas.

As industrial restructuring took hold in the 1970s, the outward-oriented suburban pattern observed for much of the post-WWII era seemed to reach its limits. New models emerged to explain the accompanying functional reorganization of urban space. Chief among these were theories associated with the 'LA School' emphasizing the sprawling, more fragmented and poly-centric nature of contemporary urban areas (see, for instance, Scott 1988, Scott and Soja 1996). More recently, Halle (2003) and Beveridge (2011) have gone back to the work of Jane Jacobs to resurrect the idea of a 'NY School' that focuses on the primacy of the downtown core as a place not just for the poor and working class but also middle and high income earners. Echoes of this 'back-to-the-city' movement are also found in Ehrenhalt's (2012) notion of a 'great inversion' which describes how North American centralcity areas are gaining in terms of affluent residents, much to the detriment of the more distant suburbs. Similarly, Florida et al. (2014) use the 'divided city' to describe how middle class neighbourhoods in large US cities are hollowing out and increasingly segregated between higher and lower income neighbourhoods. This new geographical divide reflects, they argue, the growing concentration of the affluent creative class populations in the CBDs.

\section{Existing studies of neighbourhood-level inequality in Canada}

In Canada, Bourne $(1989,1993)$ was one of the first to examine intra-urban patterns of income. His results indicated that the degree of inequality between census tracts in the country's largest metropolitan areas had increased only slightly during the decade spanning from 1971 to 1981 . He also 
recognized, however, that the geography of neighbourhood incomes was increasingly diverse and complex. In a subsequent study, MacLachlan and Sawada (1997) found that compared to the 1970s, the increase in neighbourhood inequality was more pronounced during the 1980 s decade. Not only was inequality on the rise, their analysis pointed to greater polarization of incomes across neighbourhoods. This was a particularly important finding as it highlighted the conceptual difference between inequality (i.e., an increase in the spread or dispersion of incomes) and polarization (i.e., the 'hollowing out' of the middle of the distribution and a tendency towards bimodality in the distribution).

Using newly available micro-data from the long-form Census, Myles et al. (2000) also examined intra-urban patterns of inequality through the prism of customary distributional statistics. They found that over the 1980 to 1995 period neighbourhood inequality increased in eight of Canada's largest CMAs and that much of this increase was driven by rising neighbourhood earnings inequality which was, for the most part, not offset by rising social transfers. They also found that economic segregation (the sorting effect) increased in five of eight cities examined. In a follow-up study, Chen et al. (2012) found that economic segregation increased in virtually all eight cities. That said, changes to the spatial morphology of this increase in segregation were not explicitly addressed such that the question of whether or not high and low income neighbourhoods are increasingly clustered within metropolitan space is left unanswered.

Ross et al. (2004) also use micro-data files from the Census to examine the evolution of residential segregation Canadian cities. Following Massey and Denton (1988), they adopt a number of different indices in order to capture the five basic dimensions of 'spatial variation' (i.e., evenness, exposure, concentration, centralisation and clustering) among low-income households at the census tract level. On the whole, their results point to rising economic segregation in most of the country's largest metropolitan areas._More recently, Ades et al. (2012) find that low-income populations lived in more spatially concentrated areas, many of which were located in areas near the downtown core of cities. Over time, however, they find that poverty has increased most rapidly in suburban areas outside inner-city neighbourhoods which is in-line with the back-to-the-city movement described earlier.

In addition to the cross-city comparative studies listed above, there are a number of city-specific case studies of neighbourhood inequality in Canada. The work by Walks' (2001) on Toronto is notable here. Finding evidence of increased polarization in the spatial distribution of incomes, Walks argues that the old Fordist city-suburban divide whereby low-income neighbourhoods are mainly concentrated in the downtown core and high-income neighbourhoods in the suburbs no longer applies. More recently, Hulchanski's research (2007) suggests that the city-suburban split has flipped with the emergence of 
three distinct cities within Toronto: one defined by a group of neighbourhoods experiencing rapid income growth located mainly within the city centre, a second group where neighbourhood incomes have changed very little (in areas surrounding the city centre) and a third where neighbourhood incomes have on average decreased over time (mainly in the suburbs to the north of the CBD). The same 'three cities' approach has subsequently been adopted by Ley and Lynch (2012) and Rose and TwiggeMolecey (2013) to study income dynamics in Vancouver and Montreal, respectively, where it is shown that sharp distinctions in neighbourhood incomes also exist in the former but are not as pronounced in the latter.

In a related study, Charron and Shearmur (2005) find evidence of growing income segregation in Montreal with several pockets of impoverishment appearing in the inner-ring suburbs. This leads them to propose an alternate non-linear model of the neighbourhood income gradient (see Figure 1) which resonates with the back-to-the-city and divided city models discussed earlier. Here, pockets of highincome neighbourhoods are found mainly in the gentrifying and re-gentrifying well-established innercity neighbourhoods of cities. In turn, these high-income pockets are surrounded by clusters of poorer neighbourhoods in the older suburbs and eventually further out along the more peripheral urban fringe (i.e., the new suburbs) we again find evidence of high-income clusters. Moos and Mendez (2015), in a recent study of suburban ways of living in Canada, likewise find evidence of changing and complexifying intra-metropolitan geographies of income.

[Insert Figure 1 about here]

Finally, in some of his more recent work, Walks $(2013 ; 2015$; 2016) revisits the issue of income segregation in Canadian metropolitan areas and argues for the use a new index - the coefficient of polarization (CoP) - to study how polarization is spatially expressed at the neighbourhood-level. Using this new measure, Walks shows that not only have neighbourhoods in Canada's largest metropolitan areas become more unequal over time, they are also polarizing, though the question of how neighbourhoods are sorting themselves out spatially over time remains open (p. 58). This is the key point we turn to in the following section.

\section{Some methodological considerations}

While the empirical studies mentioned above provide insights into how the distribution of incomes across neighbourhoods has changed over time, methodologically they overlook the issue of spatial 
dependence. In other words, existing studies of urban inequality and polarization in Canada (and elsewhere) have relied on conventional indices of segregation and inequality that treat neighbourhoods (i.e., census tracts) as individual observational units that are independent of each other in both a geographic and statistical sense. Even Walks' (2013) proposed CoP, which compared to other metrics provides a more balanced measure of polarization because it is less sensitive to changes in top-end incomes, does not address the potential covariation of neighbourhood incomes within geographic space. As noted earlier by Morrill (1991) and Reardon and O'Sullivan (2004), this is an issue because traditional indices of segregation reflect mainly the structural dimensions of the problem and fail to consider the geographic patterning, variations and manifestations of inequality.

To deal with the spatial dimensions of the problem, Morrill (1991) proposed the boundary modified index of dissimilarity which uses neighborhood contiguity to control for the probability of contact between income groups. This was later refined by Wong (1993) who used neighbourhood shape and common boundary length to characterize local interactions. Chakravorty (1996) also tackled the issue by developing a 'neighbourhood disparity' index that controlled for contiguity (using different types of weights) across spatial units. Applying this methodology to Philadelphia census tract level data for 1990, he found that while income disparities broadly manifested themselves as rings around the $\mathrm{CBD}$, there was much heterogeneity in terms of contiguous wealthy and poor neighbourhoods in both urban and more suburban areas of the city.

In this paper, we apply a new geovisualization technique developed by Rey et al. (2011) to examine the spatial dynamics of neighbourhood income changes in Canada's eight largest CMAs. In doing so, special emphasis is placed on understanding the directionality of movements within the income distribution over the 1991 to 2006 period. To the best of our knowledge, this is the first time a method integrating local indicators of spatial association (LISAs) with directional statistics, as well as measures that test for pattern significance, is used to explore the spatial interactions and movements in the distribution of neighbourhood incomes in a dynamic setting ${ }^{2}$.

\section{Research design}

\section{Data sources}

\footnotetext{
${ }^{2}$ Rey et al. (2011) apply this method to the study of regional income distribution dynamics across US states from 1969 to 2008 while Murray et al. (2012) use it to examine residential housing movement patterns in Franklin County Ohio over the 2004 to 2006 period.
} 
The analysis is carried out using micro-data files from the $20 \%$ long-form sample of the Canadian Census of Population for the years 1991 and $2006^{3}$. The large size of the data set (e.g., over 6.2 million observations in 2006) allows us to drill down to small geographic areas such as the census tract. For each census, income is reported for the calendar year prior to the census. The income concept used is total income which includes income derived from all sources: earnings, investment and retirement incomes, as well as government transfer payments. Total income is measured on a pre-tax basis, that is before income taxes and other deductions are taken into consideration ${ }^{4}$. We also focus our analysis on effective labour force participants between the ages of 25 and 64 who report a minimum total income of $\$ 1,000$ (Canadian). And, to ensure comparability over the period of study, we use the Consumer Price Index to deflate total income values (expressed in constant 2002 dollars).

\section{Geographic units}

Canada's eight largest metropolitan areas - Toronto, Montreal, Vancouver, Ottawa-Gatineau, Calgary, Edmonton, Quebec City and Winnipeg - are chosen for the study ${ }^{5}$. Within each of these metropolitan areas, neighbourhoods are defined at the census tract (CT) level. CTs are small, compact and relatively stable geographic areas ${ }^{6}$. In general, CTs have a population ranging between 2,500 and 8,000 persons. Over time, when the population of a CT exceeds 8,000, it may be split into two or more new census tracts. Table 1 reports the number of CTs in 1991 and 2006 for each metropolitan area and the percentage change in the number of CTs. For Winnipeg and Quebec City, where overall population growth has been more modest, the change in CT geography is small. In contrast, the number of CT splits is much higher in cities such as Vancouver, Calgary and Toronto where rates of population growth are greater.

\footnotetext{
${ }^{3}$ In 2011, the mandatory long-form Census was replaced by the voluntary National Household Survey (NHS). Since there is much more variability in the response rates of the voluntary NHS at lower levels of geography and the risk of sampling error is greater, we do not include this latest Survey in our analysis of neighbourhood disparities in order to maintain consistency and comparability over time with previous censuses (see Smith 2015).

${ }^{4}$ After-tax income is only available in the 2006 Census. While this would be the preferred income concept to use, recent studies have shown that the redistributive effects of the tax transfer system in Canada have faded since the mid-1990s (see Frenette et al. 2009; Banting and Myles 2013).

${ }^{5}$ Earlier research by Bolton and Breau (2012) has shown that with the exception of Quebec City, these CMAs were amongst those having experienced the largest increase in inequality with Calgary, Toronto and Vancouver leading the way.

${ }^{6}$ Indeed, Statistics Canada generally discourages changes to CT boundaries in order to maintain data comparability over time.
} 
[Insert Table 1 about here]

To ensure historical comparability 2006 CT splits are re-aggregated to their original 1991 geographies ${ }^{7}$. In a few instances, CT boundaries changed or new CTs were added across metropolitan areas from 1991 to 2006. A geographic information system (GIS) was used to combine those affected CTs into larger spatial entities that are longitudinally consistent across both census years. Descriptive statistics for the standardized census geographies are reported in Table 1. As expected, the average population of a CT in 2006 is larger for those cities having experienced the most important population growth rates given the re-aggregation of CTs into larger entities.

\section{Methods for exploring spatial movements in the distribution of income}

The analysis of intra-metropolitan income distribution starts by using standard techniques found in the literature on economic inequality to produce summary statistics of the distribution of income at the neighbourhood level. This allows us to replicate findings from earlier studies and to establish a-spatial or non-geographic baseline indicators of income inequality for comparison.

In order to move beyond conventional indicators and integrate the role of geography in the evolution of neighbourhood-level income distributions, we begin by following Anselin (1995) in computing Local Indicators of $\underline{\text { Spatial }}$ Association (LISA) defined as:

$$
L_{i, t}=\frac{z_{i, t} \sum_{j} w_{i, j} z_{j, t}}{\sum_{i} z_{i, t}^{2}}
$$

where $z_{i, t}$ is the median income for neighbourhood $i$ at time $t(1991,2006)$ expressed in deviations from the city-level mean and $w_{i, j}$ is an element of the spatial weights matrix defining the nature of the geographic relation between neighbours $i$ and $j$. Three different spatial weights matrices were defined for the purposes of this study (rook's, queen's and k4-nearest neighbours) though we report only results using the k4-nearest neighbour matrix to simplify the discussion ${ }^{8}$. This statistic calculates the relationship between each observation and the weighted average of its four nearest neighbors.

\footnotetext{
${ }^{7}$ Statistics Canada's naming convention uses a sequence of decimal points for each CT that allows the researcher to re-aggregate the splits to their original CT.

${ }^{8}$ Note that results using the other measures of spatial association were qualitatively similar.
} 
Using Vancouver as an example, Figure 2 (a) displays the LISA values for median neighbourhood incomes based on the Moran scatterplot for 1991 and $2006^{9}$. In each case, the four quadrants shown correspond to the four types of spatial association. The upper-right (QI) and lower-left (QIII) quadrants are of particular interest because they indicate spatial clustering of similarly high and low income values, respectively, across census tracts. In other words, QI contains neighbourhoods that have above average median incomes surrounded by neighbourhoods that also have higher than average incomes. In contrast, QIII comprises relatively poor neighbourhoods surrounded by neighbourhoods that are also relatively poor. The QII (north west) and QIV (south east) quadrants consists of census tracts with dissimilar values, either above (below) average median income neighbourhoods surrounded by below (above) average median income neighbourhoods.

Moran scatterplots for all CMAs can be generated and compared to get a general impression of how the spatial dynamics of incomes changed at the neighbourhood-level from 1991 to 2006. But as Rey et al. (2011) argue, such an exercise in comparative statics risks missing or even misidentifying the movements of individual census tracts and their neighbours within the income distribution.

[Insert Figures 2 (a) and (b) about here]

The new approach proposed by Rey et al. (2011) links Moran scatterplots across two time periods and tracks neighbourhood income changes over time as vectors. Figure 2 (b) presents the directional Moran scatterplot for Vancouver ${ }^{10}$. The plot on the left hand side of Figure 2 (b) shows the unstandardized movement vectors for each census tract. Here, each vector tells us something about the (i) direction and (ii) magnitude of change in neighbourhood incomes between 1991 (base of arrow) and 2006 (point of arrow). There is much movement both within and across quadrants over the two time periods yet the interpretation of such a graphic is difficult given the large number of vectors.

To facilitate comparisons, each vector can be standardized to the origin (i.e., beginning in 1991) as displayed on the right hand side of Figure 2 (b). When standardized, the interpretation of changes in the spatial distribution of incomes across neighbourhoods takes on new meaning. QI shows positive co-

\footnotetext{
${ }^{9}$ We chose Vancouver as an example for two main reasons: (1) as reported elsewhere (see Bolton and Breau 2012; Walks et al. 2016) Vancouver is one of the cities in Canada that experienced the largest increase in income inequality over the 1990s to mid-2000s period and (2) given the number of CTs ( $n=297)$ in the city, the information can be more easily and neatly presented in Moran scatterplots than say for cities such as Toronto and Montreal where the number of CTs is much greater (see Table 1).

${ }^{10}$ Directional LISAs were calculated using PySAL (see Rey and Anselin, 2007).
} 
movements or the relative gains of a census tract and its neighbours in the spatial distribution of incomes (i.e., neighbourhoods that are moving upwards in the distribution surrounded by neighbours that are also moving upwards on average) whereas movements in QIII represent negative comovements or relative deteriorations of census tracts and their neighbours in the distribution (i.e., moving in a downward direction in the distribution). Rose diagrams (more on this below) can also be used to summarize the frequency distribution of movement vectors across the different directions to which a simple chi-square goodness-of-fit test can be applied to draw inferences on the significance of the observed behavior compared to the expected behavior ${ }^{11}$.

\section{Results}

\section{Neighbourhood income inequality: A prologue using standard approaches}

Neighbourhood inequality is often described using quantile distributions of incomes. Mean (or median) income values for neighbourhoods are placed in ascending order, and then divided into quantiles to examine trends in income levels across low-, middle- and high-income neighbourhoods. Table 2 (a) reports a series of such summary distributional statistics for Canada's eight largest CMAs. In the first three columns, income thresholds are shown for the bottom fifth (P5), median (P50), and top fifth (P95) percentiles for each year studied. In Montreal, for instance, the poorest 5 percent of neighbourhoods had an average income of $\$ 18,100$ in 2006 whereas the richest 5 percent of neighbourhoods had an average income close to $\$ 50,000$. Overall, the table reveals considerable diversity in mean neighbourhood income cut-off values. Standard measures of dispersion indicate that (i) the range of neighbourhood mean income values has increased substantially in all eight cities from 1991 to 2006 (by more than $203 \%$ in the case of Toronto) and (ii) there is also much more variability in mean income levels within cities. Looking at the percentile ratios also tells us that the gap between the richest (top 5 percent) and poorest (bottom 5 percent) neighbourhoods has grown in all CMAs except Quebec City. This gap is especially pronounced in Toronto and Calgary where average incomes in the richest neighbourhoods are more than three times those of the poorest neighbourhoods. Looking at the P95/P50 ratios tells us the increase is driven by high-income neighbourhoods that are pulling ahead of both middle- and low-income neighbourhoods.

\footnotetext{
${ }^{11}$ See Rey et al. (2011) and Murray et al. (2012) for more methodological details.
} 
[Insert Tables 2 ( $a$ ) and (b) about here]

In addition to the percentile ratios, we include Wolfson's (1997) median/mean income ratio (shown in the last column of Table 2a) as an alternate statistic more closely related to the concept of polarization. This ratio is an indicator of the skewness of the distribution: the further the value is from 1 , the more polarized is the distribution of neighbourhood income. Again, with the exception of Quebec City, the trend towards greater income polarization across neighbourhoods appears to be quite clear.

Table 2 (b) provides further evidence that neighbourhood inequality rose in Canadian cities as both the Gini and Theil indices all register increases over the period of study ${ }^{12}$. In-line with the percentile ratios discussed above, most notable are the increases for Calgary and Toronto. The increase in Vancouver is much more pronounced here than in Table 2 (a), suggesting that the distribution of neighbourhood income varies more across the entire spectrum than simply in the tail ends. Yet so far, nothing has been said about the whether or not these changes in income are spatially dependent.

\section{The spatial dimensions of neighbourhood inequality}

In this section, we turn our attention to the underlying spatial dimensions of the neighbourhood income dynamics described above. We begin with Figures 3 (a) and (b) which present the rose diagrams for each CMA based on neighbourhood median total incomes ${ }^{13}$. Rose diagrams (or circular histograms) visually synthesize the information contained in the directional Moran scatterplots by summarizing the frequency distribution of movement vectors in different directions. For each city, the directional neighbourhood vectors are placed into one of $P=8$ classes, or circular segments, based on angular movement (Rey et al. 2011). The darker shaded circular segments are those sector counts that are found to be statistically significant at the .05 level (i.e., where the movements of a neighbourhood and its neighbours in the income distribution are spatially dependent) while the lighter shaded segments are those that are not statistically significant (i.e., spatially independent of each other). We present eightinstead of four-sector rose diagrams to provide greater detail about the differential patterns of growth and decline between a neighbourhood's median income and nearest neighbors.

\footnotetext{
${ }^{12}$ All measures of inequality were calculated in Stata using Stephen Jenkins' sumdist and ineqdeco programs (see Stata Technical Bulletin no. 48, 1999).

${ }^{13}$ We use median total incomes as our measure of central tendency to limit the influence of a few extreme outlier neighbourhood values. When replicated using mean income values, the patterns described below are typically amplified.
} 
[Insert Figures $3(\mathrm{a})$ and (b) about here]

[Insert Table 3 about here]

A number of spatial configurations are worth noting here. In particular, four of Canada's eight largest CMAs display a pattern where $90 \%$ or more of neighbourhood co-movements in the distribution of income over time are statistically significant. These cities are Montreal, Toronto, Calgary and Vancouver (see summary statistics presented in Table 3). Within each of these cities, there are two predominant directions of change. The first is captured by the positive co-movements in the upper-right quadrants of the rose diagrams where the shifts indicate the position of an individual neighbourhood and its spatial lag (i.e., neighbouring census tracts) has improved in the income distribution over the period of study. The relative gains in Montreal, Toronto, Calgary and Vancouver appear to be driven mainly by an improvement in the neighbourhood's position rather than that of its spatial lag.

What does the spatial structure of these wealthy enclaves look like? In the case of Montreal and Toronto, the u-shaped rich-poor-rich income gradient proposed by Charron and Shearmur (2005) does seem to apply (see Figures 4 (a) and (b)). In Montreal, high-income clusters are found predominantly in the middle of the island, stretching from the old port area to the Westmount and Outremont areas. On the western tip of the island we also find high-income neighbourhoods in Baie-d'Urfé, Beaconsfield and l'île-Bizard. Off island, there are numerous pockets of high-income neighbourhoods in the north and south communities part of the so-called ' 450 suburban belt' which has expanded rapidly over the last 15 to 20 years. In Toronto, wealthy neighbourhoods are very much concentrated in the city centre and midtown, wedged between the Don Valley parkway to the east and Bathurst St. to the west. These include the high-income neighbourhoods of Forest Hill South, Sunnybrook, York Mills and the Bridle Path, all of which rank among the country's wealthiest neighbourhoods. West of the city centre is another pocket of wealth around Etobicoke and in the suburban fringes of Oakville (in-line with recent findings by Moos and Mendez, 2015). In Vancouver, the neighbourhoods of Shaughnessy, West Point Grey and Kitsilano Beach are part of the city's traditionally wealthy areas to the west of the downtown core, as are North and West Vancouver across the harbour. Pockets of wealth also exist in South Surrey and Tsawwassen Beach. In all three of these cities, the geography of affluent neighbourhoods is fragmented and dispersed. The spatial organization of rich neighbourhoods in Calgary is quite different. Instead of a richpoor-rich neighbourhood income gradient, there is a more compact east-west divide across Calgary 
where high-income CTs (Britannia, Roxboro and Eagle Ridge) are mainly concentrated in the city's southwestern districts.

If the type of spatial co-movements described above were the only ones observed, and applied broadly across neighbourhoods, we could make an argument following Rey et al. (2011) that the evolution of neighbourhood income distributions is characterized by greater space-time integration or convergence. The situation however is not so simple because the other predominant direction of change moves in the opposite direction, captured by the negative co-movements in the lower-left quadrants of the rose diagrams. Here, the downward moves indicate that a CT and its nearest neighbors are losing ground in the distribution of income from 1991 to 2006. In Montreal, clusters of lower-income neighbourhoods are found in St-Michel, Montreal Nord, Hochelega and Pie-IX to the east of downtown as well as Verdun and Ville-Émard to the southwest. In Toronto, Hulchanski's (2007) 'third' city is clearly visible to the northeast (in Scarborough and Markham) and west (Glenn Park, Rockliffe and Mississauga) of the city centre. Lower-income neighbourhoods in Vancouver are mainly found in the city's east end (Strathcona, Burnaby), as is the case in Calgary in and around the airport (Northeast Calgary, Forest Heights). In other words, across all four of these cities there are as many negative co-movements as positive ones. Whatever convergence may be happening amongst neighbourhoods (whereby some poorer CTs may be catching up to others via faster growth in incomes) is countered by an equally strong pattern of divergence (i.e., neighbourhoods that are falling further behind). It is such movements in opposite directions within the distribution that provides a different perspective on the spatial dynamics of neighbourhood incomes and new evidence of the pulling apart or greater spatial polarization of incomes within metropolitan areas.

Though less pronounced, the spatial divergence of neighbourhood incomes in Ottawa-Gatineau is similar to that described above. Besides the traditional pockets of wealth found in Rockliffe Park and Old Ottawa South around Dow's Lake, what stands out in the case of Ottawa-Gatineau is the high number of neighbourhoods that are found in the southwestern quadrant of the rose diagram (see Figure 3 (a) and Table 3). The directionality of such movements within the city's distribution of income suggests that several poor census tracts and their surrounding neighbours (i.e., Castle Heights east of downtown Ottawa, as well as parts of Hull and Gatineau on the Quebec side) have lost ground relative to other neighbourhoods over the 1991 to 2006 period.

The shape of the rose diagrams for Edmonton and Winnipeg also hints at greater spatial divergence in neighbourhood incomes given that most movements across census tracts are found within quadrants I and III. However, what is interesting here is that only co-movements in quadrant III 
neighbourhoods are statistically significant (along with a few outliers in QII for Winnipeg and QIV for Edmonton). In other words, even though standard approaches to measuring neighbourhood inequality (such as the Gini coefficient or percentile ratios) are correct in pointing out that the increase in inequality across census tracts has been more moderate in these cities compared to the earlier cases discussed, they mask the fact that several neighbourhoods are nonetheless falling behind. For Winnipeg, lower-income neighbourhoods losing ground are concentrated in and around Portage and Main Streets in the downtown core, inner-city areas with a long history of income levels well below that of the CMA average (see Larch, 2015) while in Edmonton lower-income neighbourhoods lagging further behind are found in the city centre extending north of the North Saskatchewan River.

The spatial evolution of neighbourhood inequality is again different for the city of Quebec. Though the distribution of income across Quebec City changed little over time, several neighbourhoods and their surrounding areas (e.g., Basse-Ville, Limoilou and parts of Beauport) also lost ground relative to other neighbourhoods across the city.

[Insert Figures $4(\mathrm{a})$ and (b) about here]

\section{For richer or poorer? Describing neighbourhood characteristics}

While the new geovisualization method applied above allows us to better identify and describe changes in the spatial configurations of neighbourhood incomes across cities, the big question of course is why do we observe such patterns in the first place? More specifically, why do some metropolitan areas exhibit more pronounced spatial polarization of neighbourhood incomes than others? What are the attributes of neighbourhoods that are pulling ahead (QI) compared to those falling behind (QIII)? As a first attempt to answer these questions, Table 4 presents a series of key economic and sociodemographic indicators for neighbourhoods in both quadrants I and III of the rose diagrams.

Starting with the economic characteristics, neighbourhoods moving up in the distribution of income within each city have higher median total incomes than neighbourhoods moving in the other direction. Such income trajectory differences are particularly pronounced in Vancouver, Calgary and Toronto, cities that have experienced the greatest 'leaps' in income inequality. Differences in the industrial composition of neighbourhood workforces are not as pronounced, although QI CTs usually have larger shares or employees working in knowledge intensive business services (defined as accounting, legal, engineering, computer, management and scientific services). Such a finding does lend support to Florida et al.'s (2014) argument that the more affluent creative class population may play an 
important role in shaping the geography of the divided city. Much more apparent is the difference in precarious employment conditions between QI and QIII neighbourhoods. Without exception, neighbourhoods that are falling behind in the distribution of income in Canadian cities have higher shares of their workforce employed in part-time positions as well as higher unemployment rates.

[Insert Table 4 about here]

In terms of socio-demographic attributes neighbourhood differences in levels of education (i.e., bachelor's degree or more vs. less than high school) are mixed. This suggests that a simple human capital explanation of inequality (i.e., the geographic concentration of highly skilled workers with higher returns on their human capital) is not entirely compatible with the contrasting fortunes of neighbourhoods (counter to what is portrayed in Florida's divided city), at least not within the Canadian urban context. Much more striking are differences in neighbourhood ethnic and immigration composition. Across all eight cities, neighbourhoods that have lost ground within the income distribution have significantly larger shares of visible minority populations. These neighbourhoods also have much higher shares of recent immigrants (i.e., individuals arriving within five years of the 2006 Census). Smith and Ley (2008) have argued elsewhere that gateway cities such as Toronto and Vancouver have witnessed an increase in the spatial association between poverty and immigrant communities over the last few years. Our results suggest that this phenomenon, though more prominent in gateway cities, is also apparent in other metropolitan areas. QI neighbourhoods, in contrast, typically have higher shares of white and native born populations. Moreover, in cities such as Winnipeg and Edmonton, neighbourhood disparities seem to be linked to the relatively large shares of Aboriginal populations who continue to face substantial earnings disparities compared to Canadian-born majority groups (Pendakur and Pendakur, 2011). We also see evidence that neighbourhoods with higher percentages of single-headed families are part of those moving in a downward direction in the distribution of income. Finally, with the exception of Quebec City and Winnipeg, QIII neighbourhoods also have higher shares of residents under the age of 15.

\section{Conclusion}

In this paper, we apply a new approach to analyze the spatial evolution of neighbourhood income disparities across Canada's largest metropolitan areas. Three main conclusions can be drawn from our 
analysis. First, in five of Canada's eight largest metropolitan areas (Montreal, Toronto, Calgary, Vancouver and Ottawa-Gatineau), there is evidence of growing spatial divergence or polarization between neighbourhoods that have experienced positive co-movements (i.e., relative gains) and neighbourhoods that have experienced negative co-movements (i.e., relative losses) in the distribution of incomes. Neighbourhoods that have moved up in the distribution are characterised by higher median total income levels than those moving in the opposite direction. Neighbourhoods that are falling behind invariably have higher shares of their workforces employed in part-time positions and significantly higher shares of visible minority and recent immigrant populations.

Second, the geography of this spatial divergence in neighbourhood fortunes appears to become more complex over time. Where there is evidence of a rich-poor-rich income gradient in Montreal, Toronto and Vancouver, such a spatial pattern is less apparent in Ottawa-Gatineau and Calgary. In the latter, incomes are split along an east-west divide.

Third and finally, in Edmonton, Winnipeg and Quebec City, even though increases in neighbourhood inequality are less pronounced, there are clusters of neighbourhoods that are losing ground - experiencing negative co-movements - in the distribution of incomes. The presence of such clusters, which are also found in the five other cities examined, is indicative of 'spatial traps' where the nature of neighbourhood income mobility may limit the potential for distributional improvements.

Admittedly, we have only scratched the surface of the bigger question relating to why certain metropolitan areas are experiencing more pronounced spatial polarization than others. Clearly, the differences in neighbourhood mobility are explained by a combination of different causal factors which cannot be ascribed to one single theoretical paradigm. To narrow the field of potential explanations, neighbourhood level growth regressions that take into account spatial dependence could prove useful in future research on intra-metropolitan income disparities. The visible minority and immigration question also certainly warrants greater attention. In an earlier study, Walks and Maraanen (2008) argued that gentrification would likely reduce neighbourhood ethnic diversity and give way to higher spatial polarization. Our results lend support to this claim as across the eight metropolitan areas studied we find that neighbourhoods losing ground in the income distribution all have higher shares of visible minority populations. With recent findings showing that higher levels of immigration are tied to declines in the earnings and labour market performance of immigrants (Hou and Picot 2014), we can expect this will lead to more spatial polarization within Canadian cities in the near future. The recent refugee resettlement program will also have an impact on the urban form of inequality for years to come. 
Finally, the analysis carried out also demonstrates the usefulness of Rey et al.'s (2011) approach when applied to a granular data set. By providing new insights on the directionality of change in the spatial configurations of neighbourhood inequality, our work also underlines the importance of comparative research in urban studies to understand how prevailing structures of social stratification have an impact on neighbourhood formation (Scott and Storper 2015). 


\section{References}

Ades, J., Apparicio, P. and A.M. Seguin (2012) Are new patterns of low-income distribution emerging in Canadian metropolitan areas? Canadian Geographer, 56: 339-361.

Anselin, L. (1995) Local Indicators of Spatial Association - LISA. Geographical Analysis, 27: 93-115.

Banting, K. and J. Myles eds. (2013) Inequality and the fading of redistributive politics. Vancouver, BC: UBC Press.

Beveridge, A. (2011) Commonalities and contrasts in the development of major United States urban areas: A spatial and temporal analysis from 1910 to 2000, in M. P. Gutmann et al. (eds.), Navigating time and space in population studies, pp.185-216, Springer.

Bolton, K. and S. Breau (2012) Growing Unequal? Changes in the Distribution of Earnings across Canadian Cities. Urban Studies, 49: 1377-1396.

Breau, S. (2014) The Occupy Movement and the top 1\% in Canada. Antipode, 46: 13-33.

Bourne, L. S. (1989) Are New Urban Forms Emerging - Empirical Tests for Canadian Urban Areas. Canadian Geographer, 33: 312-328.

Bourne, L. S. (1993) Close Together and Worlds Apart - An Analysis of Changes in the Ecology of Income in Canadian Cities. Urban Studies, 30: 1293-1317.

Chakravorty, S. (1996) A measurement of spatial disparity: The case of income inequality. Urban Studies, 33: 1671-1686.

Charron, M. and R. Shearmur (2005) Economic segregation as a complex phenomenon: A space-time analysis of the Montreal case. Canadian Geographer, 49: 332-351.

Chen, W. H., Myles, J. and G. Picot (2012) Why Have Poorer Neighbourhoods Stagnated Economically while the Richer Have Flourished? Neighbourhood Income Inequality in Canadian Cities. Urban Studies, 49:877-896.

Ehrenhalt, A. (2012) The great inversion and the future of the American city. NY: Alfred A. Knopf.

Florida, R., Matheson, Z., Adler, P. and T. Brydges (2014) The divided city and the shape of the new metropolis. Martin Prosperity Institute, University of Toronto.

Fortin, N., Green, D. A., Lemieux, T., Milligan, K. and W. C. Riddell (2012) Canadian Inequality: Recent Developments and Policy Options. Canadian Public Policy, 38: 121-145.

Green, D.A., Riddell, W.C. and F. St-Hilaire eds. (2016) Income inequality: The Canadian story. Montreal, QC: Institute for Research on Public Policy. 
Harris, C.D. and E.L. Ullman (1945) The nature of cities. Annals of the American Academy of Political and Social Science, 24: 7-17.

Hou, F, and G. Picot (2014) Annual levels of immigration and immigrant entry earnings in Canada. Canadian Public Policy, 40(2): 166-181.

Hoyt, H. (1939) The structure and growth of American residential neighborhoods in American cities. Washington, DC: Federal Housing Admnistration.

Hulchanski, D. (2007) The three cities within Toronto: Income polarization among Toronto's neighbourhoods, 1970-2000. Research Bulletin No. 41. Centre for Urban and Community Studies. University of Toronto, Toronto: ON.

Jargowsky, P.A. (1996) Take the money and run: Economic segregation in US metropolitan areas. American Sociological Review, 61: 984-998.

Larch, B. (2015) Spatial polarization of income in a slow-growth city, in Distasio, J. and A. Kaufman (Eds.) The divided prairie city. Institute of Urban studies, University of Winnipeg, 14-25.

Ley, D. and N. Lynch (2012) Divisions and Disparities in Lotus-Land: Socio-Spatial Income Polarization in Greater Vancouver, 1970-2005. Research Paper No. 223, Cities Centre, University of Toronto, Toronto: ON.

MacLachlan, I. and R. Sawada (1997) Measures of income inequality and social polarization in Canadian Metropolitan Areas. Canadian Geographer, 41: 377-397.

Massey, D.S. and N.A. Denton (1988) The Dimensions of Residential Segregation. Social Forces, 67: 281315.

Moos, M. and P. Mendez (2015) Suburban ways of living and the geography of income: How homeownership, single-family dwellings and automobile use define the metropolitan social space. Urban Studies, 52: 1864-1882.

Morrill, R. L. (1991) On the measure of geographic segregation. Geography Research Forum, 11: 25-36. Murray, A.T., Liu, Y., Rey, S. J. and L. Anselin (2012) Exploring movement object patterns. Annals of Regional Science, 49: 471-484.

Myles, J., Picot G. and W. Pyper (2000) Neighbourhood inequality in Canadian cities. Research Paper No. 160, Statistics Canada, Ottawa, ON.

OECD (2014) Economic Surveys, 2014 - Canada. Paris: OECD.

Park, R.E. and E.W. Burgess eds. (1925) The city. University of Chicago Press.

Pendakur, K. and R. Pendakur (2011) Aboriginal income disparity in Canada. Canadian Public Policy. 37: 61-83. 
Rey, S. J. (2001) Spatial empirics for economic growth and convergence. Geographical Analysis, 33: 195214.

Rey, S. J., Murray, A. T., and L. Anselin (2011) Visualizing regional income distribution dynamics. Letters in Spatial and Resource Sciences, 4: 81-90.

Rey, S. and L. Anselin (2007) PySAL: A Python library of spatial analytical methods. Review of Regional Studies, 37(1): 5-27.

Rose, D. and A. Twigge-Molecey (2013) A City-Region Growing Apart? Taking Stock of Income Disparity in Greater Montréal, 1970-2005. Research Paper No. 222, Cities Centre, University of Toronto, Toronto: ON.

Ross, N. A., Houle, C., Dunn, J. R. and M. Aye (2004) Dimensions and dynamics of residential segregation by income in urban Canada, 1991-1996. Canadian Geographer, 48: 433-445.

Scott, A.J. (1988) Metropolis: From the division of labor to urban form. UC Press.

Scott, A.J. and E. Soja eds. (1996) The city: Los Angeles and urban theory at the end of the twentieth century, UC Press.

Scott, A.J. and M. Storper (2015) The nature of cities: The scope and limits of urban theory. International Journal of Urban and Regional Research, doi:10.1111/1468-2427.12134.

Smith, W. (2015) The 2011 National Household Survey-the complete statistical story (see http://www.statcan.gc.ca/eng/blog-blogue/cs-sc/2011NHSstory, published on June $\left.4^{\text {th }}, 2015\right)$.

Veall, M. R. (2012) Top income shares in Canada: Recent trends and policy implications. Canadian Journal of Economics, 45: 1247-1272.

Walks, R. A. (2001) The social ecology of the post-Fordist/global city? Economic restructuring and sociospatial polarisation in the Toronto urban region. Urban Studies, 38:4 07-447.

Walks, R. A. (2013) Income Inequality and Polarization in Canada's Cities: An Examination and New Form of Measurement. Research Paper No. 27, Cities Centre, University of Toronto, Toronto: ON.

Walks, R.A. (2015) Growing divisions: Inequality, neighbourhood poverty, and homelessness in the Canadian city, in Filion, P. Moos, M., Vinodrai, T. and R. Walker (eds.), Canadian cities in transition: Perspectives for an urban age. Oxford University Press, 150-174.

Walks, R.A., Dinca-Panaitescu, M. and D. Symone (2016). Income inequality and polarization in the city of Toronto and York region. Research Paper No. 238, Cities Centre, University of Toronto, Toronto: ON.

White, M. (1983) Measures of spatial segregation. American Journal of Sociology, 88: 1008-1018. 
Wolfson, M. C. (1997) Divergent inequalities: Theory and empirical results. Review of Income and Wealth 4: 401-421.

Wong, D. W. S. (1993) Spatial Indexes of Segregation. Urban Studies, 30: 559-5. 
Figure 1. The new neighbourhood income gradient

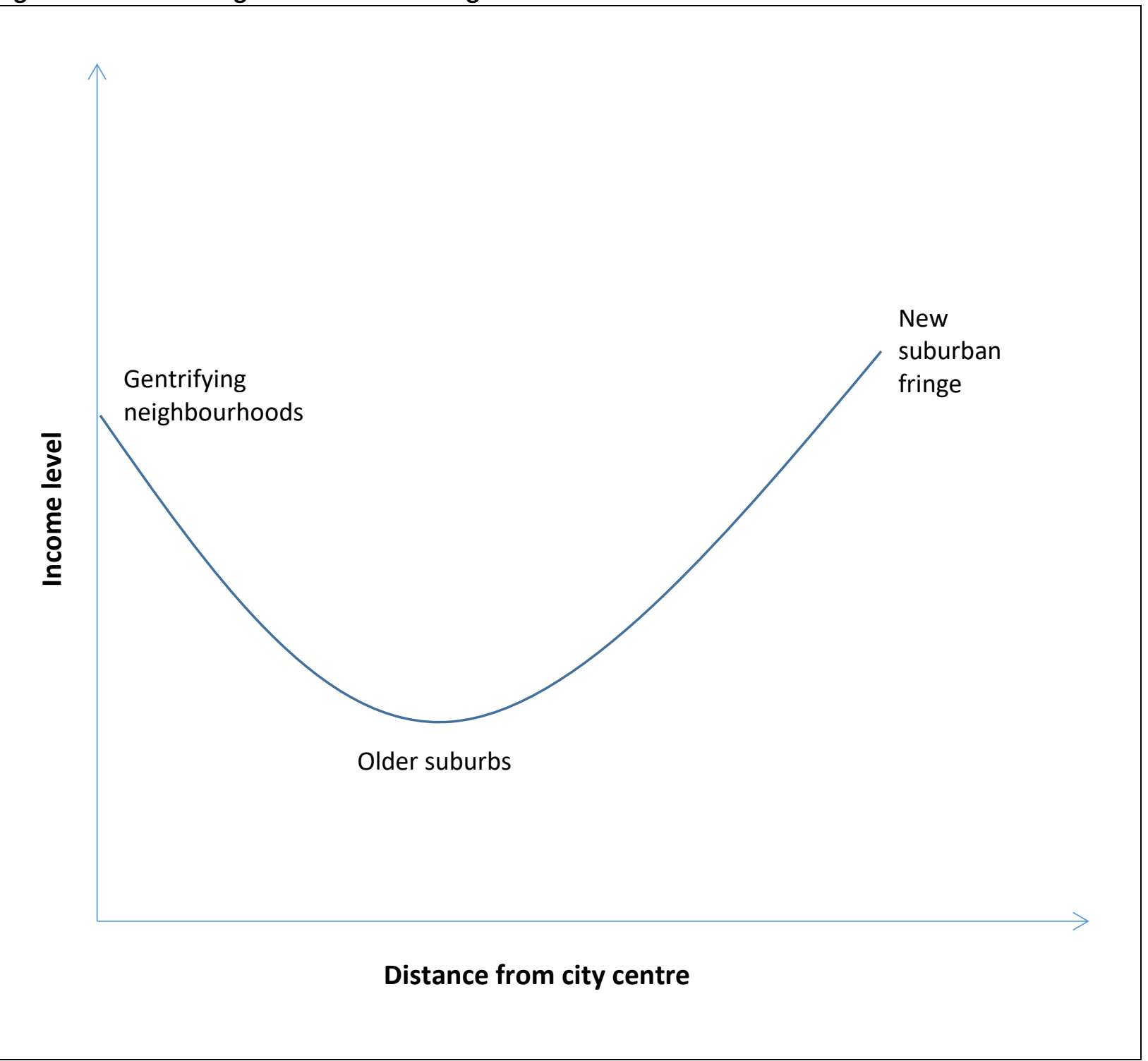

Source: Adapted from Charron and Shearmur (2005) 
Figure 2 (a). Moran scatterplot for Vancouver

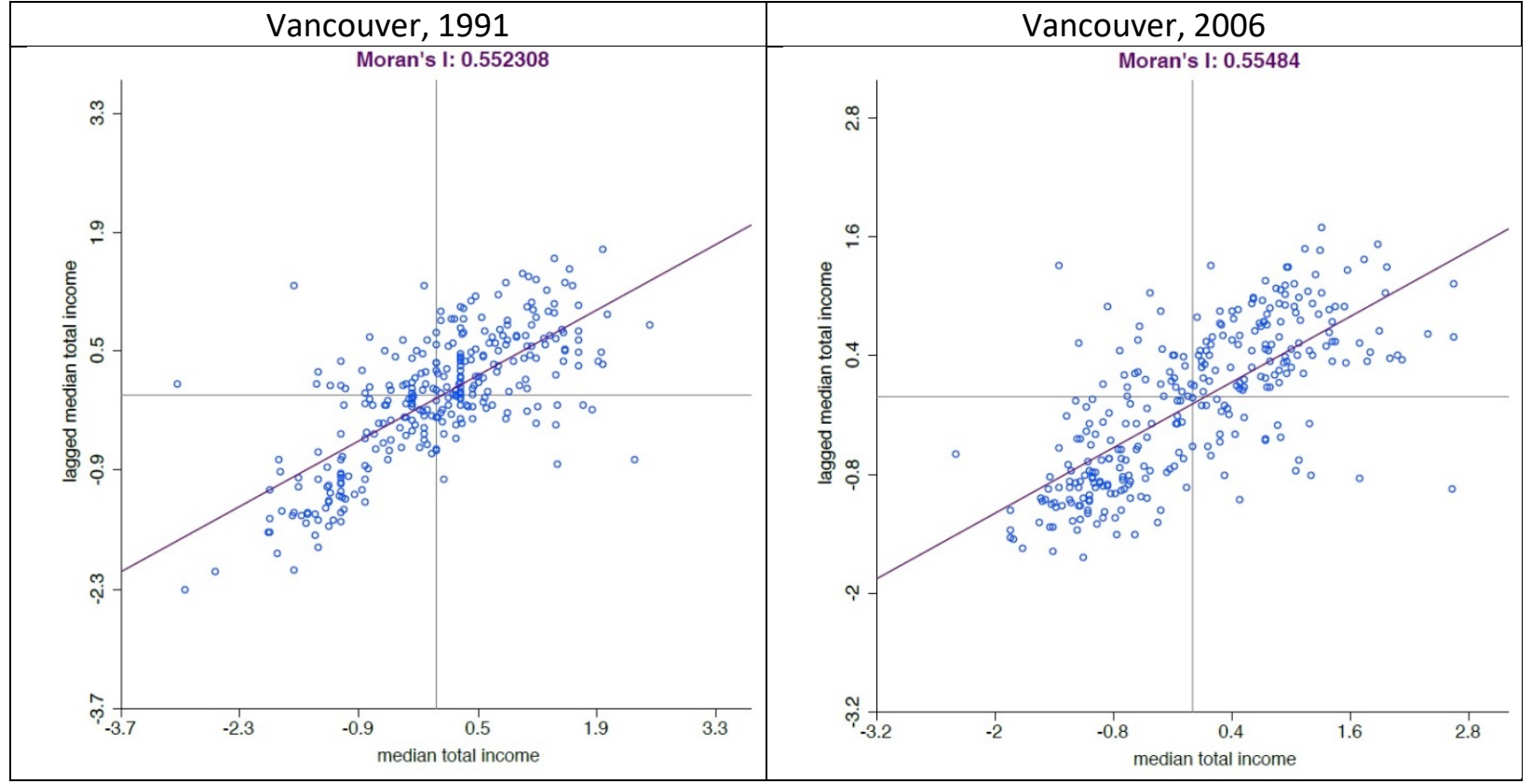

Notes: Based on $k 4$ nearest neighbour spatial weights matrix.

Figure $\mathbf{2}$ (b). Directional Moran scatterplot for Vancouver

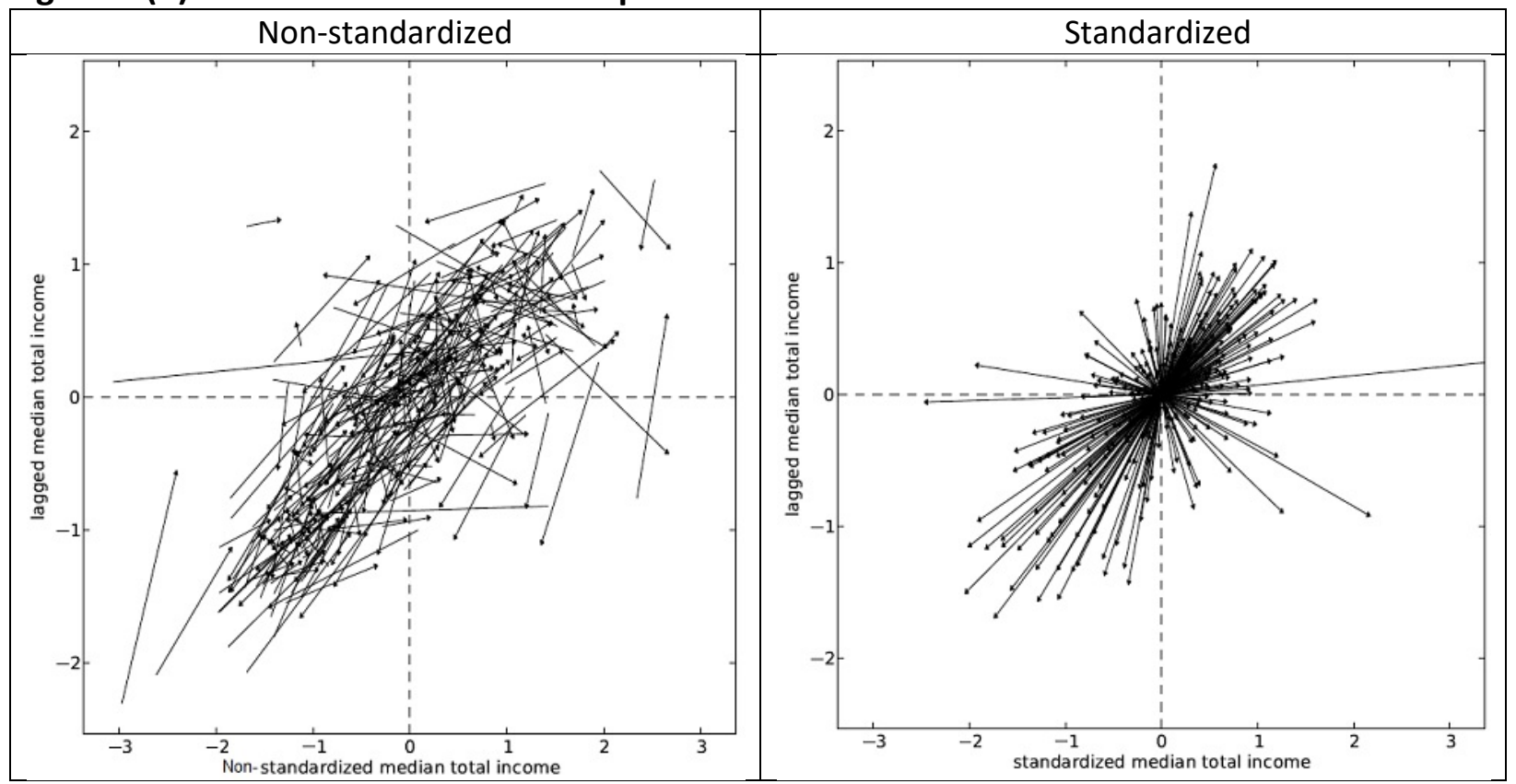


Figure 3 (a). Rose diagrams: Summary of Moran movement vectors

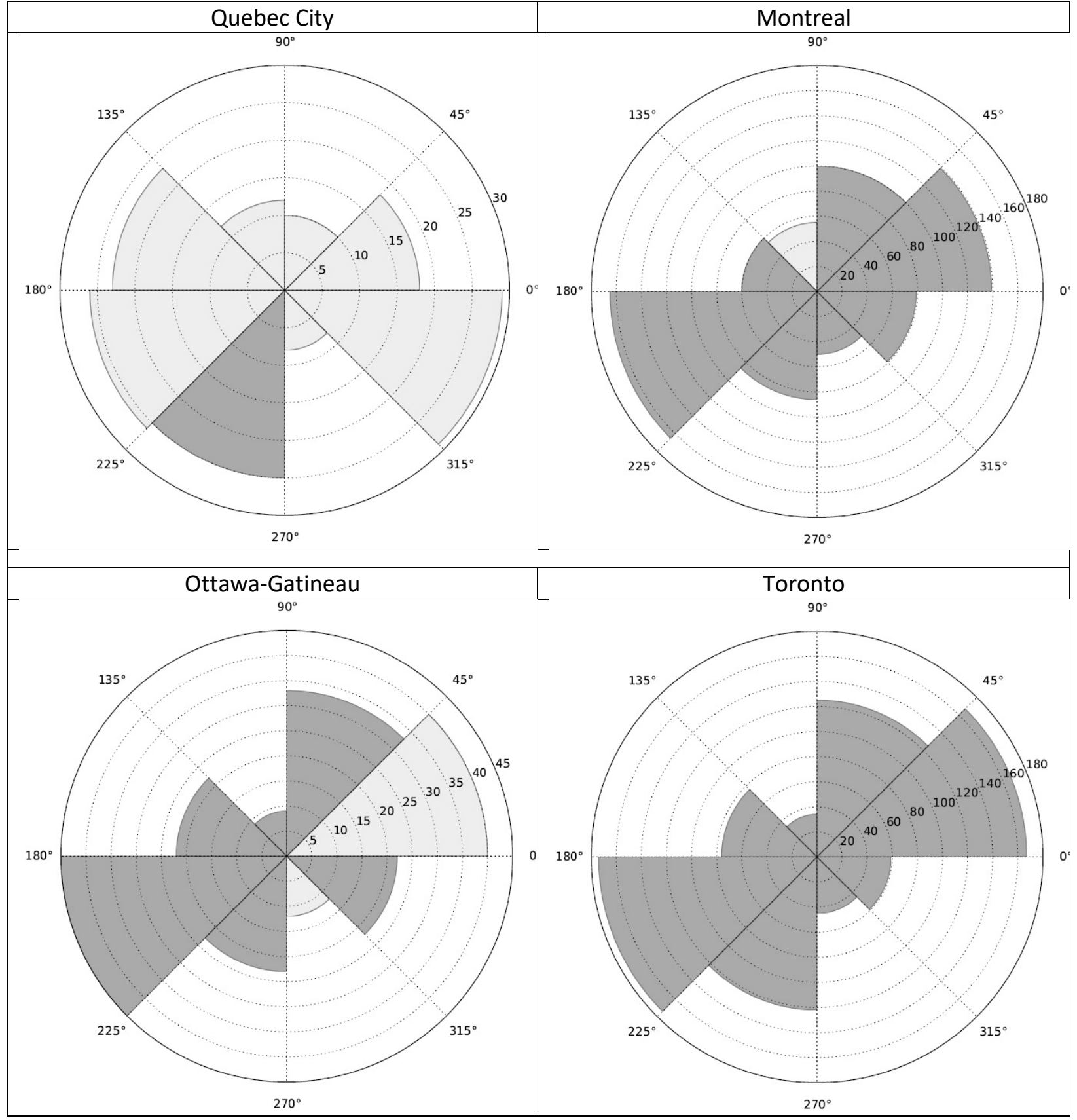


Figure 3 (b). Rose diagrams: Summary of Moran movement vectors

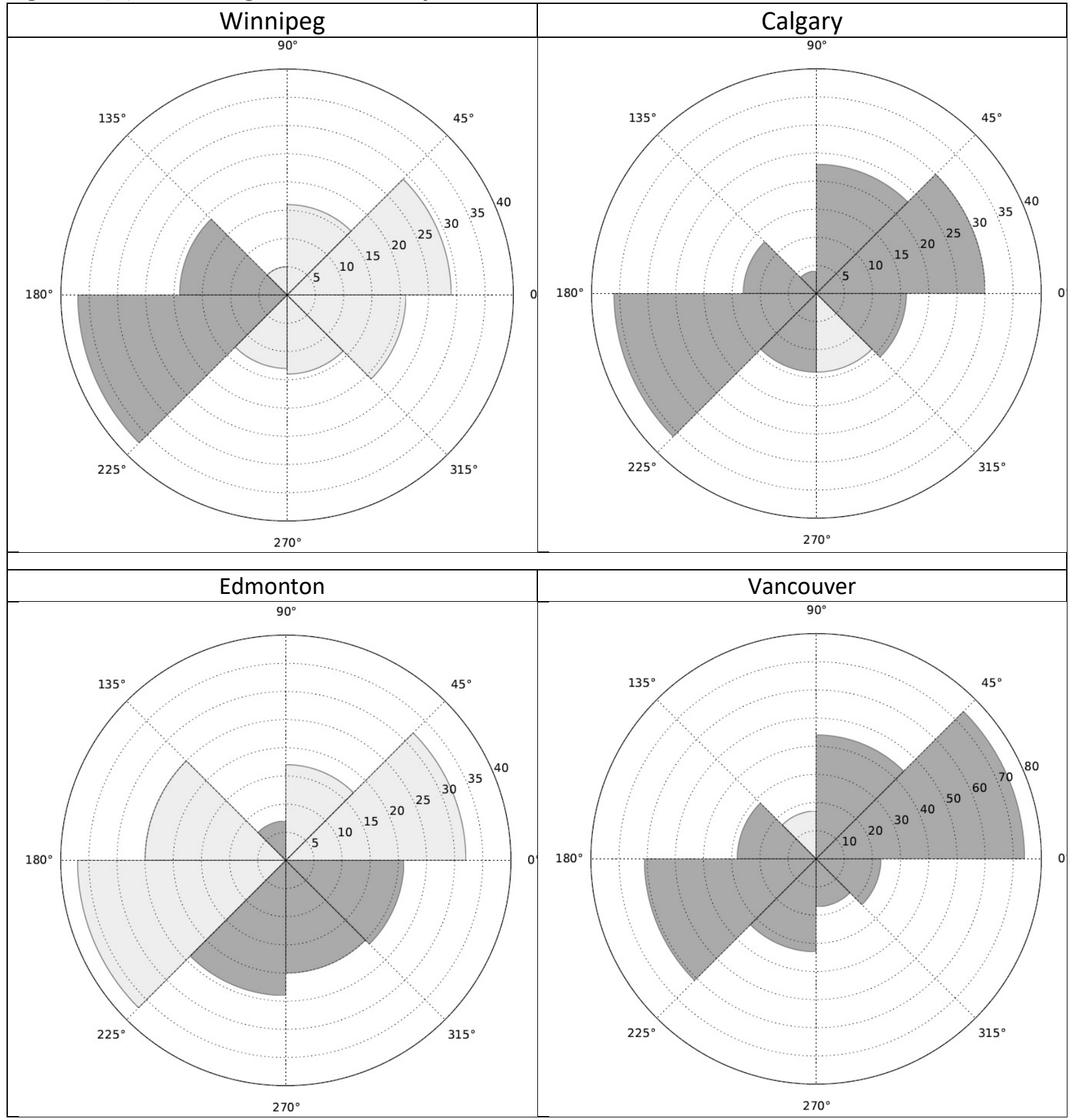


Figure 4 (a). Local indicators of spatial association for median neighbourhood incomes, 2006

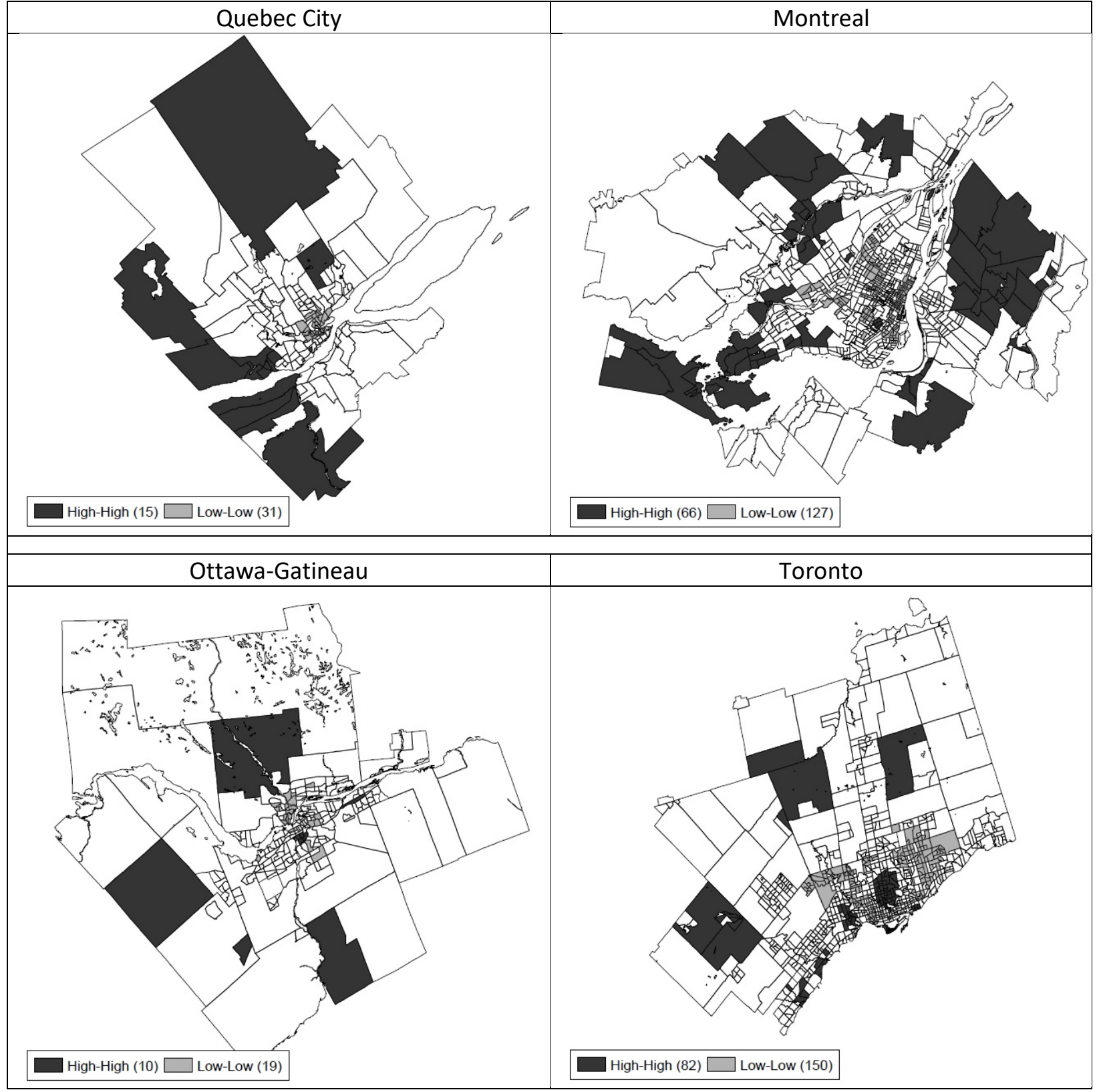


Figure 4 (b). Local indicators of spatial association for median neighbourhood incomes, 2006

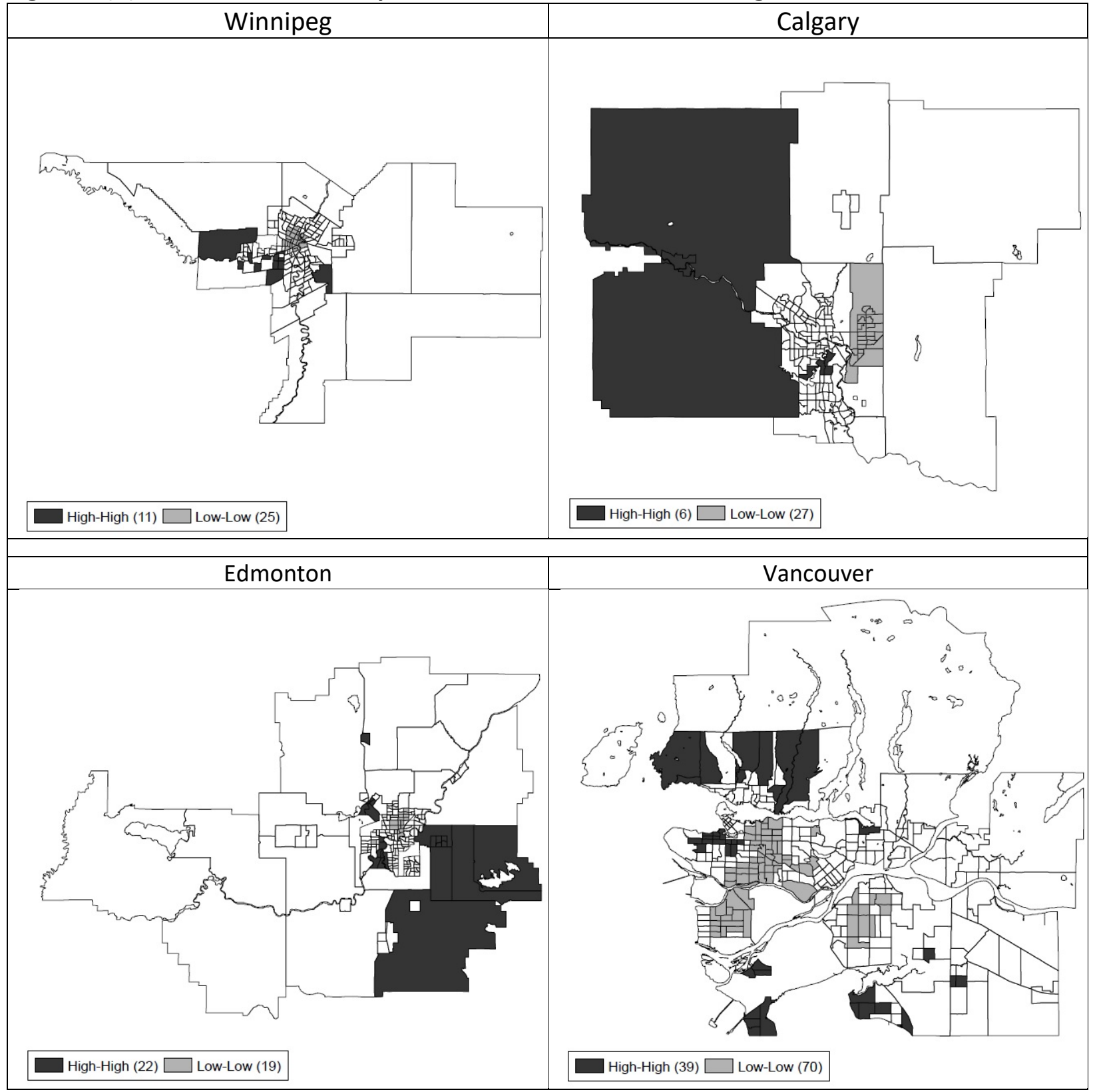


Table 1: 1991 and 2006 census tract geography

\begin{tabular}{|c|c|c|c|c|c|c|c|}
\hline & \multicolumn{3}{|c|}{ Census geography } & \multicolumn{4}{|c|}{ Standardized census geography } \\
\hline & \multicolumn{3}{|c|}{ Number of census tracts } & \multirow[b]{2}{*}{ \# of CTs } & \multicolumn{3}{|c|}{ Average population of census tract } \\
\hline & 1991 & 2006 & $\%$ change & & 1991 & 2006 & $\%$ change \\
\hline Quebec & 152 & 166 & 9.2 & 151 & 4,222 & 4,635 & 9.8 \\
\hline Montreal & 749 & 878 & 17.2 & 734 & 4,211 & 4,702 & 11.7 \\
\hline Ottawa-Gatineau & 211 & 251 & 18.9 & 206 & 4,426 & 5,267 & 19.0 \\
\hline Toronto & 812 & 1,003 & 23.5 & 802 & 4,816 & 6,274 & 30.3 \\
\hline Winnipeg & 156 & 168 & 7.7 & 154 & 4,189 & 4,350 & 3.8 \\
\hline Calgary & 153 & 203 & 32.7 & 150 & 4,988 & 7,064 & 41.6 \\
\hline Edmonton & 195 & 229 & 17.4 & 183 & 4,545 & 5,591 & 23.0 \\
\hline Vancouver & 299 & 410 & 37.1 & 297 & 5,333 & 7,063 & 32.4 \\
\hline
\end{tabular}

Table 2 (a). Summary distributional statistics, mean neighbourhood income (in thousands of constant \$2002)

\begin{tabular}{|c|c|c|c|c|c|c|c|c|c|}
\hline & \multicolumn{3}{|c|}{ Percentiles } & \multicolumn{2}{|c|}{ Dispersion } & \multicolumn{4}{|c|}{ Ratios } \\
\hline & P5 & P50 & P95 & Range & $\mathrm{CV}$ & P95/P5 & P95/P50 & P50/P5 & Median/mean \\
\hline \multicolumn{10}{|l|}{ Quebec } \\
\hline 1991 & $\$ 16.4$ & $\$ 23.9$ & $\$ 34.1$ & $\$ 28.7$ & .212 & 2.1 & 1.4 & 1.5 & .964 \\
\hline 2006 & $\$ 20.1$ & $\$ 29.3$ & $\$ 41.9$ & $\$ 39.9$ & .226 & 2.1 & 1.4 & 1.5 & .975 \\
\hline \multicolumn{10}{|c|}{ Montreal } \\
\hline 1991 & $\$ 16.3$ & $\$ 24.4$ & $\$ 38.6$ & $\$ 81.4$ & .299 & 2.4 & 1.6 & 1.5 & .966 \\
\hline 2006 & $\$ 18.1$ & $\$ 28.2$ & $\$ 49.4$ & $\$ 194.8$ & .380 & 2.7 & 1.8 & 1.6 & .935 \\
\hline \multicolumn{10}{|c|}{$\begin{array}{l}\text { Ottawa- } \\
\text { Gatineau }\end{array}$} \\
\hline 1991 & $\$ 22.4$ & $\$ 32.4$ & $\$ 43.8$ & $\$ 68.3$ & .219 & 2.0 & 1.4 & 1.4 & .993 \\
\hline 2006 & $\$ 22.5$ & $\$ 35.5$ & $\$ 49.9$ & $\$ 98.5$ & .257 & 2.2 & 1.4 & 1.6 & .967 \\
\hline \multicolumn{10}{|l|}{ Toronto } \\
\hline 1991 & $\$ 20.7$ & $\$ 30.0$ & $\$ 50.2$ & $\$ 82.3$ & .313 & 2.4 & 1.7 & 1.4 & .940 \\
\hline 2006 & $\$ 20.6$ & $\$ 31.0$ & $\$ 65.3$ & $\$ 250.1$ & .529 & 3.2 & 2.1 & 1.5 & .881 \\
\hline \multicolumn{10}{|c|}{ Winnipeg } \\
\hline 1991 & $\$ 16.7$ & $\$ 25.5$ & $\$ 39.2$ & $\$ 47.9$ & .267 & 2.3 & 1.5 & 1.5 & .962 \\
\hline 2006 & $\$ 17.4$ & $\$ 28.1$ & $\$ 42.6$ & $\$ 65.6$ & .310 & 2.4 & 1.5 & 1.6 & .945 \\
\hline \multicolumn{10}{|l|}{ Calgary } \\
\hline 1991 & $\$ 21.7$ & $\$ 30.2$ & $\$ 46.7$ & $\$ 51.2$ & .259 & 2.1 & 1.5 & 1.4 & .938 \\
\hline 2006 & $\$ 23.8$ & $\$ 38.1$ & $\$ 75.4$ & $\$ 124.2$ & .426 & 3.2 & 2.0 & 1.6 & .913 \\
\hline \multicolumn{10}{|c|}{ Edmonton } \\
\hline 1991 & $\$ 20.3$ & $\$ 27.2$ & $\$ 42.3$ & $\$ 40.2$ & .228 & 2.1 & 1.6 & 1.3 & .959 \\
\hline 2006 & $\$ 23.2$ & $\$ 32.7$ & $\$ 52.9$ & $\$ 57.3$ & .261 & 2.3 & 1.6 & 1.4 & .951 \\
\hline \multicolumn{10}{|c|}{ Vancouver } \\
\hline 1991 & $\$ 20.3$ & $\$ 28.4$ & $\$ 41.3$ & $\$ 56.2$ & .245 & 2.0 & 1.4 & 1.4 & .964 \\
\hline 2006 & $\$ 20.6$ & $\$ 29.0$ & $\$ 47.9$ & $\$ 145.6$ & .373 & 2.3 & 1.6 & 1.4 & .918 \\
\hline
\end{tabular}

Notes: Percentiles are calculated using neighbourhood population weights. 
Table 2 (b). Neighbourhood inequality, 1991 - 2006

\begin{tabular}{lccccccc}
\hline \hline & \multicolumn{3}{c}{ Gini } & & \multicolumn{3}{c}{ Theil } \\
\cline { 2 - 4 } \cline { 7 - 8 } & 1991 & 2006 & \% change & & 1991 & 2006 & \% change \\
\hline Quebec & .114 & .122 & 6.5 & & .022 & .024 & 12.4 \\
Montreal & .147 & .172 & 17.2 & & .039 & .056 & 44.5 \\
Ottawa-Gatineau & .118 & .136 & 14.5 & & .023 & .031 & 34.1 \\
Toronto & .155 & .217 & 39.8 & & .043 & .098 & 128.0 \\
Winnipeg & .139 & .159 & 15.1 & & .034 & .043 & 28.4 \\
Calgary & .138 & .207 & 49.5 & & .031 & .076 & 142.1 \\
Edmonton & .118 & .139 & 17.7 & & .024 & .031 & 30.7 \\
Vancouver & .128 & .167 & 30.2 & & .028 & .053 & 91.4 \\
\hline
\end{tabular}

Notes: Both indices of neighbourhood inequality are computed using neighbourhood population weights.

Table 3. Summary of directional LISAs, median total income

\begin{tabular}{lccccccc}
\hline \hline & \# CTs & $\boldsymbol{p}<.05$ & \% sign. & QI & QII & QIII & QIV \\
\hline Quebec & 151 & 25 & 16.6 & & & 25 & \\
Montreal & 734 & 679 & 92.5 & 239 & 60 & 251 & 129 \\
Ottawa- & 206 & 154 & 74.8 & 33 & 31 & 68 & 22 \\
Gatineau & & & & & & & \\
Toronto & 802 & 802 & 100 & 292 & 110 & 296 & 104 \\
Winnipeg & 154 & 56 & 36.4 & & 19 & 37 & \\
Calgary & 150 & 136 & 90.7 & 53 & 17 & 50 & 16 \\
Edmonton & 183 & 72 & 39.3 & & 7 & 24 & 41 \\
Vancouver & 297 & 280 & 94.2 & 118 & 28 & 94 & 40 \\
\hline
\end{tabular}

Notes: $p<.05$ represents the number of census tracts for which the directional LISA

is statistically significant; \% sign. denotes the percentage of census tracts which have significant co-movements. 
Table 4. Characteristics of QI and QIII neighbourhoods, 2006

\begin{tabular}{|c|c|c|c|c|c|c|c|c|c|c|c|c|c|c|c|c|}
\hline & \multicolumn{2}{|c|}{ Quebec City } & \multicolumn{2}{|c|}{ Montreal } & \multicolumn{2}{|c|}{$\begin{array}{l}\text { Ottawa- } \\
\text { Gatineau }\end{array}$} & \multicolumn{2}{|c|}{ Toronto } & \multicolumn{2}{|c|}{ Winnipeg } & \multicolumn{2}{|c|}{ Calgary } & \multicolumn{2}{|c|}{ Edmonton } & \multicolumn{2}{|c|}{ Vancouver } \\
\hline & $\mathrm{QI}^{*}$ & QIII & QI & QIII & QI & QIII & QI & QIII & QI* & QIII & QI & QIII & $\mathrm{QI}^{*}$ & QIII & QI & QIII \\
\hline$\#$ of $\mathrm{CTs}^{\S}$ & & 25 & 239 & 251 & 33 & 68 & 292 & 296 & & 37 & 53 & 50 & & 24 & 118 & 94 \\
\hline \multicolumn{17}{|l|}{ Economic characteristics } \\
\hline Median total income & 25972 & 20800 & 21648 & 19655 & 27009 & 26958 & 24684 & 21407 & 24488 & 22961 & 27065 & 23574 & 25975 & 24211 & 23954 & 19575 \\
\hline$\%$ manufacturing & 8.0 & 8.6 & 11.3 & 12.9 & 3.8 & 4.6 & 11.5 & 13.1 & 11.6 & 11.2 & 6.4 & 7.3 & 7.9 & 8.6 & 8.3 & 7.6 \\
\hline$\%$ KIBS+ & 6.9 & 6.9 & 9.1 & 8.7 & 9.2 & 8.6 & 10.1 & 9.6 & 4.9 & 5.6 & 12.9 & 10.6 & 6.4 & 6.2 & 9.0 & 10.1 \\
\hline$\%$ government & 15.4 & 10.5 & 4.7 & 3.4 & 21.3 & 20.2 & 3.6 & 3.1 & 7.1 & 7.0 & 2.9 & 2.8 & 6.4 & 6.5 & 3.8 & 3.6 \\
\hline Female participation rate & 46.7 & 48.7 & 46.9 & 47.7 & 48.7 & 49.0 & 48.0 & 48.1 & 47.4 & 48.6 & 45.5 & 46.8 & 45.9 & 46.6 & 48.2 & 47.8 \\
\hline$\%$ Part-time & 17.8 & 19.4 & 18.2 & 19.3 & 19.1 & 20.2 & 18.1 & 18.4 & 19.4 & 20.3 & 16.8 & 20.0 & 19.0 & 19.6 & 20.9 & 22.8 \\
\hline Unemployment rate (\%) & 4.8 & 6.0 & 7.3 & 8.6 & 6.4 & 6.1 & 6.4 & 7.4 & 5.0 & 5.5 & 3.9 & 4.5 & 4.3 & 5.4 & 5.4 & 5.8 \\
\hline \multicolumn{17}{|l|}{$\begin{array}{l}\text { Socio-demographic } \\
\text { characteristics }\end{array}$} \\
\hline$\%$ visible minority & 1.8 & 2.4 & 10.5 & 24.7 & 14.4 & 14.8 & 27.2 & 48.8 & 10.8 & 19.6 & 13.3 & 23.3 & 5.7 & 20.4 & 31.7 & 47.9 \\
\hline$\%$ recent immigrants & 1.3 & 1.3 & 4.2 & 7.2 & 3.5 & 2.6 & 5.7 & 11.1 & 2.3 & 5.1 & 4.7 & 5.4 & 1.4 & 3.6 & 5.2 & 8.2 \\
\hline$\%$ higher education & 27.5 & 22.7 & 28.5 & 29.3 & 38.0 & 27.9 & 32.5 & 33.3 & 17.3 & 23.4 & 32.2 & 25.7 & 16.4 & 18.4 & 28.1 & 32.7 \\
\hline$\%$ no high school & 11.8 & 12.4 & 14.6 & 13.8 & 12.7 & 14.4 & 15.3 & 12.0 & 21.2 & 17.0 & 14.4 & 17.6 & 22.5 & 20.0 & 13.3 & 10.2 \\
\hline$\%$ single-headed family & 5.2 & 6.4 & 5.9 & 6.4 & 5.7 & 6.3 & 5.9 & 5.8 & 6.6 & 6.2 & 4.7 & 5.8 & 5.4 & 6.4 & 4.8 & 4.8 \\
\hline$\%$ young $(<15)$ & 15.6 & 12.9 & 15.0 & 16.0 & 14.3 & 17.1 & 16.9 & 17.3 & 18.0 & 16.3 & 13.2 & 18.4 & 18.5 & 19.1 & 15.1 & 16.1 \\
\hline$\%$ senior (>64) & 13.5 & 17.1 & 11.0 & 15.8 & 14.0 & 12.2 & 13.1 & 12.4 & 13.8 & 13.1 & 11.8 & 9.6 & 11.8 & 11.5 & 13.0 & 13.0 \\
\hline
\end{tabular}

Notes: Mean values are presented for each characteristic with the exception of median total income (where the median value is reported). ${ }^{\S}$ represents the number of census tracts that are statistically significant $(p<.05)$ in the local indicators of dynamic spatial association. * For Quebec, Winnipeg and Edmonton, there are no statistically significant directional LISAs in QI. For comparative purposes, we show the mean values of characteristics for those non-significant QI neighbourhoods. + KIBS stands for knowledge intensive business services. 